\title{
MicroRNA-615-5p regulates the proliferation and apoptosis of breast cancer cells by targeting HSF1
}

\author{
KAISHENG LIU and RONG MA \\ Department of Breast Surgery, Qilu Hospital of Shandong University, Jinan, Shandong 250012, P.R. China
}

Received July 25, 2018; Accepted January 31, 2019

DOI: $10.3892 / \mathrm{etm} .2021 .9624$

\begin{abstract}
Breast cancer, which commonly occurs in the epithelium of the mammary gland, is a malignant tumor. MicroRNAs are involved in various cancer-associated processes, and microRNA-615-5p has been identified to be decreased in the pathological tissues from patients with breast cancer. In the present study, the possible mechanism of microRNA-615-5p in the progression of breast cancer was investigated in order to identify potential novel targets for clinical treatment. Heat shock factor 1 (HSF1) was identified as a predictive target gene of microRNA-615-5p using TargetScan analysis. The expression levels of microRNA-615-5p and its target gene, HSF1, were measured in breast cancer tissues and normal adjacent tissues. Additionally, the effects of microRNA-615-5p on MCF-7 breast cancer cell growth and apoptosis were examined. Furthermore, the interaction between HSF1 and microRNA-615-5p was investigated by a dual luciferase gene reporter assay. The expression levels of HSF1 were measured following transfection with microRNA-615-5p or pcDNA3.1-HSF1. Finally, the expression levels of proliferationand apoptosis-associated factors such as B-cell lymphoma 2 (Bcl-2), cyclin D1, proliferating cell nuclear antigen (PCNA) and bcl-2-like protein 4 (Bax) were determined. The results demonstrated that lower microRNA-615-5p expression and higher HSF1 mRNA expression were present in tumor tissues compared with adjacent tissues $(\mathrm{P}<0.01)$. HSF1 was verified as a direct target of microRNA-615-5p using the dual luciferase gene reporter assay. In comparison with untransfected control and mimic-transfected negative control (NC) cells, MCF-7 cells transfected with microRNA-615-5p mimics exhibited reduced cell proliferation and increased apoptosis $(\mathrm{P}<0.01)$. However, the overexpression of HSF1 using a vector reversed the suppression of HSF1 induced by microRNA-615-5p mimics $(\mathrm{P}<0.01)$. The mRNA and protein expression levels
\end{abstract}

Correspondence to: Dr Rong Ma, Department of Breast Surgery, Qilu Hospital of Shandong University, 107 Wenhua West Road, Jinan, Shandong 250012, P.R. China

E-mail: marong6666@yeah.net

Key words: microRNA-615-5p, heat shock factor 1, breast cancer, proliferation, apoptosis of Bax were significantly increased, whereas those of Bcl-2, cyclin D1 and PCNA were decreased in the cells transfected with microRNA-615-5p mimics compared with the control and NC cells $(\mathrm{P}<0.01)$. Collectively, the present study indicated that microRNA-615-5p may mediate the progression of breast cancer by targeting HSF1.

\section{Introduction}

Breast cancer is a malignant tumor and the second most common cause of cancer-associated mortality worldwide (1). Breast cancer may spread to distant organs via metastasis, and $90 \%$ of breast cancer mortalities are attributable to metastasis (2). At present, the pathogenesis and mechanism of breast cancer remain unclear; therefore, elucidation of the pathogenesis of breast cancer is urgently necessary in order to determine specific novel targets for the diagnosis and treatment of breast cancer.

MicroRNAs (miRs) are single-stranded non-coding RNAs that may recognize specific target mRNAs at the post-transcriptional level (3). The expression levels of the target genes are downregulated via the promotion of mRNA degradation and/or inhibition of the translation process (4). Furthermore, there is evidence to suggest that microRNAs may serve as suppressors or promoters in the development of various types of cancer. For example, the overexpression of miR-3196 suppresses breast cancer cell proliferation and induces apoptosis through targeting ERBB3 (5), whereas miR-24-3p has been reported to promote breast cancer cell proliferation and inhibit apoptosis by targeting p27Kip1 (6). In a previous study, microRNA-615 was identified to be downregulated in breast cancer, suggesting that microRNA-615 is a potential tumor suppressor in breast cancer (7). Furthermore, miR-615-5p may also suppress cell proliferation and invasion in lung cancer (8) and pancreatic ductal adenocarcinoma (9). However, to the best of our knowledge, the association between breast cancer and the ectopic expression of microRNA-615-5p has not yet been elucidated.

In the present study, heat shock factor (HSF1) was identified as a target gene of microRNA-615-5p, and the regulatory mechanism and expression of microRNA-615-5p and HSF1 were examined. The results of the present study demonstrated that microRNA-615-5p may function as a tumor suppressor and may provide a theoretical basis for the early diagnosis and treatment of breast cancer. 


\section{Materials and methods}

Specimens. A total of 40 pairs of breast cancer tissues and normal adjacent breast tissues were obtained from Qilu Hospital of Shandong University (Jinan, China) between June 2015 and January 2016. The patients comprised 40 females, whose mean age was $47.2 \pm 7.3$ years. All patients were pathologically diagnosed with breast cancer (Table 1) and had not received chemotherapy or radiotherapy prior to the present study. Written consent was obtained from each patient. The present study was approved by the Ethics Committee of Qilu Hospital of Shandong University.

Cell culture. The MCF-7 human breast cancer cell line (Type Culture Collection of the Chinese Academy of Sciences, Shanghai, China) was cultured in RPMI-1640 (Gibco; Thermo Fisher Scientific, Inc., Waltham, MA, USA) supplemented with $10 \%$ fetal bovine serum (Invitrogen; Thermo Fisher Scientific, Inc.), and $1 \%$ penicillin and streptomycin. The cells were cultured at $37^{\circ} \mathrm{C}$ in a $5 \% \mathrm{CO}_{2}$ humidified incubator.

Transfection efficiency of microRNA-615-5p. The MCF-7 cells were divided into three groups: i) Control group (untreated); ii) negative control (NC) group (transfected with microRNA-615-5p mimics NC); and iii) mimics group (transfected with microRNA-615-5p mimics). The MCF-7 cells were seeded onto six-well plates at a density of $1 \times 10^{5}$ cells/well, and $50 \mathrm{nmol} / 1$ oligonucleotide (microRNA-615-5p mimics or NC) were subsequently transfected into cells using Lipofectamine 2000 (Invitrogen; Thermo Fisher Scientific, Inc.), according to the manufacturer's protocol. The microRNA-615-5p mimics and NC oligonucleotides were purchased from Shanghai GenePharma Co., Ltd. (Shanghai, China). The sequences of the miR-615-5p mimics were as follows: 5'-GGGGGUCCCCGGUGCUCGGAUC-3' (sense) and 5'-UCCGAGCACCGGGGACCCCCUU-3' (anti-sense). The sequences of the NC were as follows: 5'-UUCUCCGAA CGUGUCACGUTT-3' (sense) and 5'-ACGUGACACGUU CGGAGAATT-3' (anti-sense).

Transfection efficiency of HSF1. The MCF-7 cells were divided into three groups: i) Control group (untreated); ii) pcDNA3.1 group (transfected with pcDNA3.1); and iii) pcDNA3.1-HSF1 group (transfected with pcDNA3.1-HSF1). The cells were seeded onto six-well plates at a density of $2 \times 10^{4}$ cells/well, and $2 \mu \mathrm{g} / \mathrm{ml} \mathrm{pcDNA3.1} \mathrm{(Thermo} \mathrm{Fisher} \mathrm{Scientific,} \mathrm{Inc.,} \mathrm{Waltham,}$ MA, USA) or pcDNA3.1-HSF1 was subsequently transfected into the cells using Lipofectamine ${ }^{\circledR} 2000$ (Invitrogen; Thermo Fisher Scientific, Inc.) according to the manufacturer's protocol.

Vector construction and co-transfection assay. The HSF1-expression vector was constructed by inserting HSF1 into a pcDNA3.1 vector. In brief, HSF1 cDNA was amplified by polymerase chain reaction (PCR) from the cDNA of MCF-10A cells (Bena Culture Collection, Beijing, China). The HSF1 cDNA was then inserted into pcDNA3.1 (Thermo Fisher Scientific, Inc.) to construct a pcDNA3.1-HSF1 expression vector. To evaluate whether or not HSF1 overexpression attenuates the microRNA-615-5p-induced suppression of HSF1, MCF-7 cells were divided into three different groups: i) $\mathrm{NC}$ group (microRNA-615-5p mimics $\mathrm{NC}$ ); ii) mimics group (transfected with microRNA-615-5p mimics); and iii) mimics + HSF1 group (transfected with microRNA-615-5p mimics and pcDNA3.1-HSF1). Briefly, cells were seeded onto six-well plates at a density of $1 \times 10^{5}$ cells/well, and co-transfected with $50 \mathrm{nmol} / 1 \mathrm{NC}$ or microRNA-615-5p mimics with or without $2 \mu \mathrm{g} / \mathrm{ml}$ pcDNA3.1-HSF1 using Lipofectamine ${ }^{\circledR} 2000$ (Invitrogen; Thermo Fisher Scientific, Inc.), according to the manufacturer's protocol.

Analysis of cell proliferation. Following $24 \mathrm{~h}$ of transfection, the cells were washed with PBS, re-seeded onto a 96-well plate at a density of $1 \times 10^{4}$ cells/well and cultured in fresh RPMI-1640 medium for 12, 24 or $48 \mathrm{~h}$. Subsequently, a Cell Counting kit-8 (CCK-8) cell proliferation assay was conducted using the CCK-8 kit (Dojindo Molecular Technologies Inc., Kumamoto, Japan). The absorbance of each well was measured at $450 \mathrm{~nm}$ using a microplate reader.

Analysis of cell apoptosis. At $48 \mathrm{~h}$ post-transfection, the MCF-7 cells were washed with PBS. An Annexin V-fluorescein isothiocyanate (FITC) apoptosis kit (BD Biosciences, San Jose, CA, USA) was used to quantify apoptotic MCF-7 breast cancer cells by flow cytometry (FACSCalibur, BD Biosciences) using Cell Quest Pro software (version 6.0; BD Biosciences), according to the manufacturer's protocol.

$R N A$ extraction and reverse transcription-quantitative PCR $(R T-q P C R)$. Total RNA was extracted from patient tissue samples and MCF-7 cells using a microRNAeasy kit (Invitrogen; Thermo Fisher Scientific, Inc.), according to the manufacturer's protocol. To quantify the microRNA-615-5p and HSF1 mRNA expression in the 40 paired tumor and adjacent tissue samples and MCF-7 cells at $48 \mathrm{~h}$ post-transfection. In total, $2 \mu \mathrm{l}$ RNA was isolated from the adjacent and tumor samples and reverse transcribed into cDNA using the TaqMan MicroRNA RT kit (Applied Biosystems; Thermo Fisher Scientific, Inc.), according to the manufacturer's protocol. qPCR step was subsequently performed using TaqMan Universal Master mix (Thermo Fisher Scientific, Inc.). In total, $2 \mu \mathrm{l}$ cDNA, $10 \mu 1$ TaqMan Universal Master mix, $1 \mu 1$ primers and nuclease-free $\mathrm{H}_{2} \mathrm{O}$. The primer sequences used were as follows: microRNA-615-5p forward, 5'-GCCAGCCACCAAGAAGC-3' and reverse, 5'-GCTCCC GCTGTTTACTCTG-3'; U6 forward, 5'-GCTTCGGCAGCA CATATACTAAAAT-3' and reverse, 5'-CGCTTCACGAAT TTGCGTGTCAT-3'; HSF1 forward, 5'-GCCTTCCTGACC AAGCTGT-3' and reverse, 5'-GTCGAACACGTGGAAGCT GT-3'; Bcl-2 forward, 5'-ACAACATCGCCCTGTGGATGA C-3' and reverse, 5'-ATAGCTGATTCGACGTTTTGCC-3'; cyclin D1 forward, 5'-CCTGTCCTACTACCGCCTCA-3' and reverse, 5'-TCCTCCTCTTCCTCCTCCTC-3'; PCNA forward, 5'-CTCCAACTTCTGGGCTCAAG-3' and reverse, 5'-GTA AACGGACTGCTGGAGGA-3'; Bax forward, 5'-GGAATT CTGACGGCAACTTCAACTGGG-3' and reverse, 5'-GGA ATTCTTCCAGATGGTGAGCGAGG-3'; GAPDH forward, 5'-GAAGGTGAAGGTCGGAGTC-3' and reverse 5'-GAA GATGGTGATGGGATTTC- 3 '. The thermocycling conditions used were as follows: Initial denaturation at $95^{\circ} \mathrm{C}$ for $10 \mathrm{~min} ; 40$ cycles of $95^{\circ} \mathrm{C}$ for $10 \mathrm{sec}$ and $62^{\circ} \mathrm{C}$ for $15 \mathrm{sec}$. U6 small nuclear RNA and GAPDH were used as the endogenous 
Table I. Association between miR-615-5p expression status and clinicopathological features of patients with breast cancer.

\begin{tabular}{|c|c|c|c|c|}
\hline \multirow[b]{2}{*}{ Clinicopathological feature } & \multirow[b]{2}{*}{ Cases } & \multicolumn{2}{|c|}{ Expression level } & \multirow[b]{2}{*}{ P-value } \\
\hline & & High miR-615-5p $(n=10)$ & Low miR-615-5p $(\mathrm{n}=30)$ & \\
\hline Age & & & & 0.271 \\
\hline$\leq 60$ years & 22 & 4 & 18 & \\
\hline$>60$ years & 18 & 6 & 12 & \\
\hline Tumor size & & & & 0.000 \\
\hline$\geq 2 \mathrm{~cm}$ & 29 & 3 & 26 & \\
\hline$>2 \mathrm{~cm}$ & 11 & 7 & 4 & \\
\hline Tumor location & & & & 0.361 \\
\hline Left & 21 & 4 & 17 & \\
\hline Right & 19 & 6 & 13 & \\
\hline ER status & & & & 0.714 \\
\hline Negative & 22 & 6 & 16 & \\
\hline Positive & 18 & 4 & 14 & \\
\hline TNM stage & & & & 0.126 \\
\hline $\mathrm{I} / \mathrm{II}$ & 31 & 6 & 25 & \\
\hline III/IV & 9 & 4 & 5 & \\
\hline Lymph node metastasis & & & & 0.002 \\
\hline Negative & 7 & 5 & 2 & \\
\hline Positive & 33 & 5 & 28 & \\
\hline
\end{tabular}

ER, estrogen receptor; TNM, tumor, node and metastasis.

controls. The relative expression level of microRNA-615-5p was normalized to U6, while the expression levels of HSF1, B-cell lymphoma 2 (Bcl-2), cyclin D1, proliferating cell nuclear antigen (PCNA) and Bcl-2-associated X protein (Bax) were normalized to GAPDH using the $2^{-\Delta \Delta \mathrm{Cq}}$ method (10).

Western blot analysis. Total protein was extracted from different groups of treated MCF-7 cells $48 \mathrm{~h}$ post-transfection using M-PER protein extraction reagent (Pierce; Thermo Fisher Scientific, Inc.) supplemented with a protease mimics cocktail (Thermo Fisher Scientific, Inc.). Total protein was quantified using the Bradford method and $10 \mu \mathrm{g}$ protein/lane was separated via SDS-PAGE on a $10 \%$ gel (Thermo Fisher Scientific, Inc.), according to the manufacturer's protocol. The separated proteins were transferred onto polyvinylidene fluoride membranes (Shanghai Ofluorine Chemical Technology Co., Ltd., Shanghai, China) and blocked in $5 \%$ nonfat milk for $2 \mathrm{~h}$ at $37^{\circ} \mathrm{C}$. The membranes were incubated overnight at $4^{\circ} \mathrm{C}$ with the following primary antibodies: Mouse anti-HSF1 (1:1,000; cat. no. ab201978; Abcam, Cambridge, UK), mouse anti-Bcl-2 (1:1,000; cat. no. ab692; Abcam), rabbit anti-cyclin D1 (1:100; cat. no. ab16663; Abcam), mouse anti-PCNA (1:1,000; cat. no. ab29; Abcam), rabbit anti-Bax (1:1,000; cat. no. ab32503; Abcam) and mouse anti-GAPDH (1:1,000; cat. no. ab8245; Abcam). Subsequent to washing, the membranes were incubated for $1 \mathrm{~h}$ at $37^{\circ} \mathrm{C}$ with horseradish peroxidase (HRP)-labeled goat anti-rabbit $\operatorname{IgG}(1: 1,000$; cat. no. A0208; Beyotime, Shanghai, China) and HRP-labeled goat anti-mouse secondary antibody (1:1,000; cat. no. A0216; Beyotime, Shanghai, China). Subsequent to washing, $200 \mu \mathrm{l}$
Abcam Chemiluminescent Horseradish Peroxidase Substrate (Abcam) was added to the membrane surface. The signals were captured and the intensity of the bands was quantified. ImageJ software (version 1.49; National Institutes of Health, Bethesda, MD, USA) was used to determine the protein expression levels of HSF1, Bcl-2, PCNA, cyclin D1 and Bax relative to those of GAPDH. GAPDH served as the internal control.

Dual luciferase reporter assay. TargetScan bioinformatics analysis (www.targetscan.org) was used to identify HSF1 as a potential target of miR-615-5p (11). The 293 cells (Type Culture Collection of the Chinese Academy of Sciences) were seeded onto a six-well plate at a density of $1 \times 10^{5}$ cells/well and transfected with the wild-type (WT) HSF1 3'untranslated region (UTR; WT HSF1-3'UTR) or mutant HSF1 3'UTR (MUT HSF1 3'UTR) in combination with either NC or microRNA-615-5p mimics using Lipofectamine ${ }^{\circledR}$ RNAi Max (Thermo Fisher Scientific, Inc.). Transfected cells were subsequently incubated at $37^{\circ} \mathrm{C}$ for $48 \mathrm{~h}$ and the luciferase activity was examined using a Dual-Luciferase Reporter kit (Beyotime Institute of Biotechnology, Haimen, China). Firefly luciferase activity was normalized to Renilla luciferase activity.

Statistical analysis. SPSS version 22.0 (IBM Corp., Armonk, NY, USA) was used to analyze the results. Data are presented as the mean \pm standard deviation. Statistical comparisons between two groups were conducted using Student's t-test, while one-way analysis of variance followed by Newman-Keuls tests was used to analyze differences among three or more groups. 

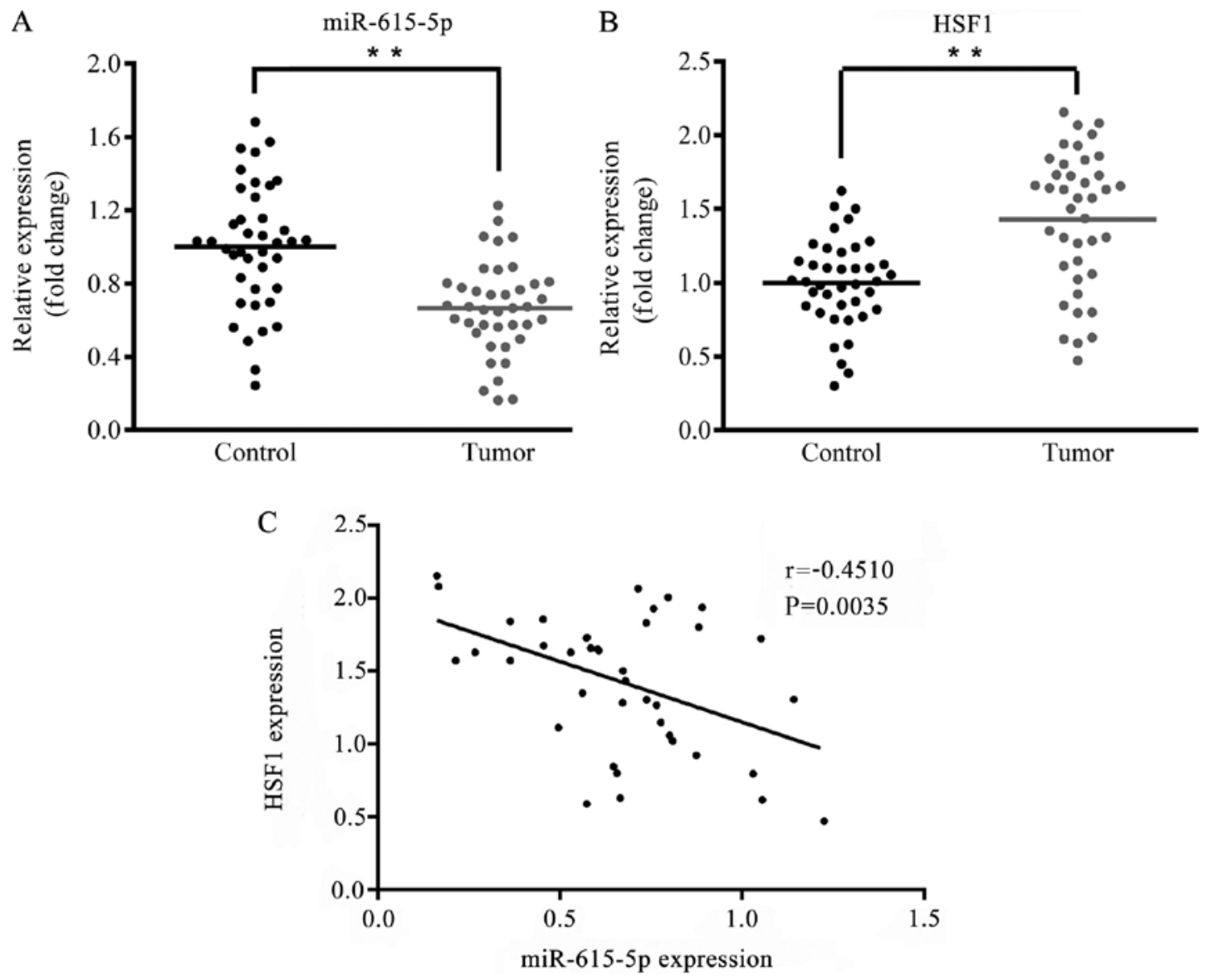

Figure 1. Comparison of the relative expression of miR-615-5p and HSF1 in breast cancer tissues and adjacent tissues. Relative expression of (A) miR-615-5p and (B) HSF1 mRNA in breast cancer tissues and adjacent tissues. (C) Results of Pearson's correlation analysis between the expression of miR-615-5p and the expression of HSF1 in patients with breast cancer. ${ }^{* *} \mathrm{P}<0.01$, tumor vs. control group. Control, adjacent non-tumor tissues; tumor, breast cancer tumor tissues; miR, microRNA; HSF1, heat shock factor 1.

Pearson's correlation analyses were performed to evaluate the correlation between miR-615-5p and HSF1. P<0.05 was considered to indicate a statistically significant difference.

\section{Results}

Expression of microRNA-615-5p and HSF1 in breast cancer and adjacent tissues. Using the online bioinformatics tool TargetScan, HSF1 was predicted as a potential target gene of microRNA-615-5p. To verify the biological functions of microRNA-615-5p and HSF1 in the development of breast cancer, the expression levels of microRNA-615-5p and HSF1 in the breast cancer tissues and normal adjacent tissues from 40 patients were compared. As presented in Fig. 1A and B, in tumor tissues the expression level of microRNA-615-5p was significantly decreased $(\mathrm{P}<0.01)$ whereas the expression level of HSF1 mRNA was significantly increased $(\mathrm{P}<0.01)$ compared with the respective levels in the normal adjacent tissues. Furthermore, Pearson's correlation analysis indicated that the expression levels of microRNA-615-5p and HSF1 were negatively correlated (Fig. 1C; $r=-0.4510, \mathrm{P}=0.0035$ ).

Transfection efficiency of microRNA-615-5p and HSF1. As shown in Fig. 2A, the expression level of microRNA-615-5p was significantly higher in the mimics group compared with the NC group $(\mathrm{P}<0.01)$, and no significant difference was detected between the control and NC groups. Furthermore, the expression level of HSF1 was significantly increased in the pcDNA3.1-HSF1 group compared with the pcDNA3.1 and control groups (Fig. 2B; $\mathrm{P}<0.01$ ).

Effect of microRNA-615-5p on the proliferation of MCF-7 cells. A CCK-8 assay was performed to investigate the effect of microRNA-615-5p on breast cancer cell growth. The results demonstrated that there was no significant difference in the proliferation rate between the control and $\mathrm{NC}$ groups during the 48-h test period (Fig. 3; P>0.05). However, at 24 and $48 \mathrm{~h}$, the cells transfected with microRNA-615-5p-mimics presented significantly decreased proliferation compared with the control groups (Fig. 3; $\mathrm{P}<0.01$ ).

Effect of microRNA-615-5p on the apoptosis of MCF-7 cells. To investigate the effect of microRNA-615-5p on breast cancer cell apoptosis, an Annexin V-FITC apoptosis kit was used to examine the apoptosis of the cells in different groups (Fig. 4A-C). The apoptotic rates of the control and NC groups were $\sim 1.28$ and $1.39 \%$, respectively; the rate of apoptosis in the microRNA-615-5p mimics group was $\sim 18$-fold higher, and was significantly increased compared that in with the control groups ( $\mathrm{P}<0.01$; Fig. 4D). 

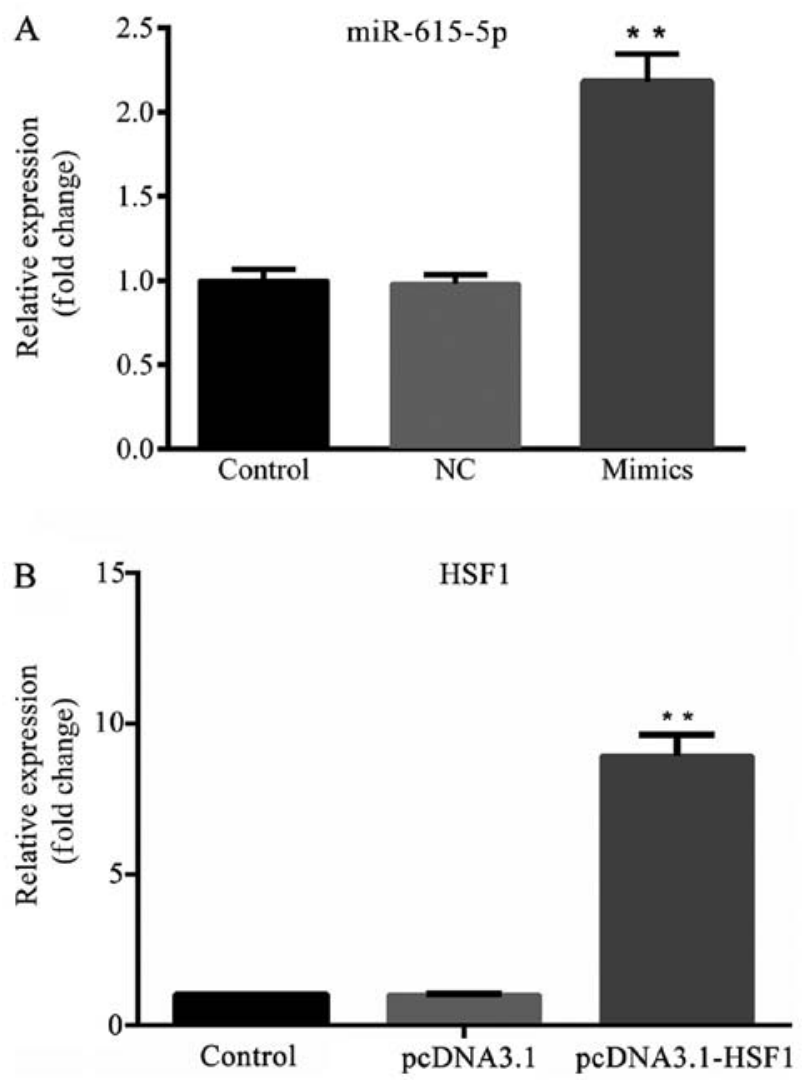

Figure 2. Transfection efficiency of microRNA-615-5p and HSF1. Relative expression levels of (A) microRNA-615-5p and (B) HSF1 mRNA in different groups. ${ }^{* *} \mathrm{P}<0.01$, mimics vs. NC group; pcDNA3.1-HSF1 vs. pcDNA3.1 group. miR, microRNA; control, untransfected cells; mimics, microRNA-615-5p mimics-transfected cells; NC, microRNA-615-5p negative control-transfected cells; HSF1, heat shock factor 1 .

HSF1 overexpression attenuates the microRNA-615-5p-induced suppression of HSF1. As shown in Fig. 5A, the mRNA expression level of HSF1 was significantly decreased in the microRNA-615-5p mimics group compared with the $\mathrm{NC}$ group $(\mathrm{P}<0.01)$. However, the reduction in HSF1 expression was attenuated by the co-transfection of pcDNA3.1-HSF1 $(\mathrm{P}<0.01)$. The western blotting results for HSF1 protein presented a trend of variation similar to that of the mRNA $(\mathrm{P}<0.01$; Fig. 5B and $\mathrm{C})$.

HSF1 is a direct target of microRNA-615-5p in breast cancer. The interaction between HSF1 and microRNA-615-5p was examined using a dual luciferase gene reporter assay. The results demonstrated that the transfection of microRNA-615-5p significantly restrained the luciferase activity in the WT HSF1 3'UTR plasmid-transfected cells $(\mathrm{P}<0.01)$, whereas microRNA-615-5p had no significant effect on the MUT HSF1 3'UTR plasmid-transfected cells (Fig. 6).

Effect of microRNA-615-5p on the expression levels of Bcl-2, cyclin D1, PCNA and Bax. In order to investigate the effect of microRNA-615-5p on proliferation- and apoptosis-associated factors, the mRNA and protein expression levels of Bcl-2, cyclin D1, PCNA and Bax were tested. The RT-qPCR data demonstrate that in the microRNA-615-5p mimics group, the mRNA expression levels of Bcl-2, cyclin D1 and PCNA

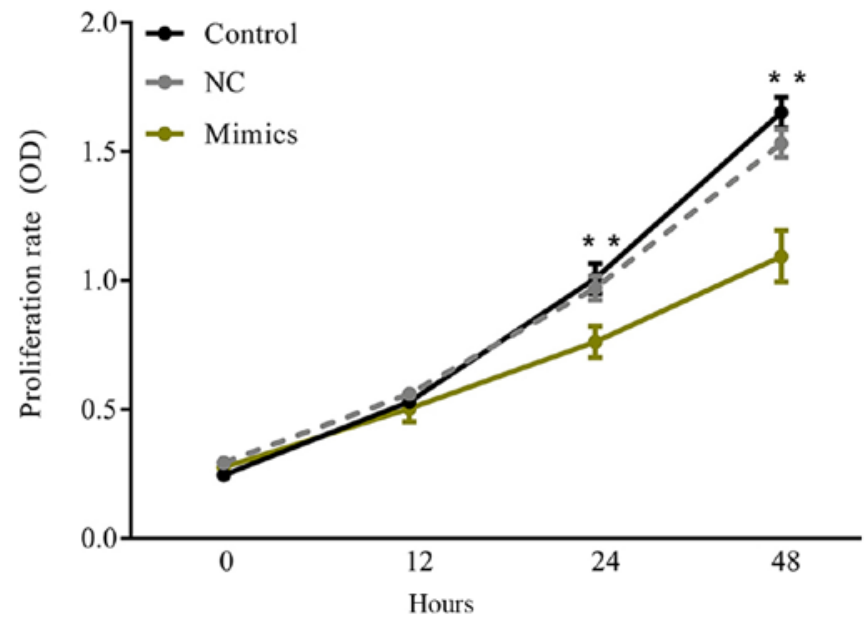

Figure 3. Effect of microRNA-615-5p on the proliferation of MCF-7 cells Proliferation rate of $\mathrm{MCF}-7$ cells in different groups. ${ }^{* *} \mathrm{P}<0.01$, mimics vs. NC group. miR, microRNA; control, untransfected cells; mimics, microRNA-615-5p mimics-transfected cells; NC, microRNA-615-5p negative control-transfected cells.

were significantly decreased, whereas the expression level of Bax was significantly increased compared with the respective levels in the control groups $(\mathrm{P}<0.01$; Fig. 7). Furthermore, the protein expression levels exhibited the same trend of variation as the mRNA results $(\mathrm{P}<0.01 ;$ Fig. 8$)$.

\section{Discussion}

In the present study, the effects of microRNA-615-5p on the progression of breast cancer at the cellular level were investigated via the transfection of microRNA-615-5p mimics into MCF-7 cells. The results demonstrated that the overexpression of microRNA-615-5p suppressed the growth and promoted the apoptosis of MCF-7 cells. In addition, bioinformatic analysis predicted that HSF1 was a target gene of microRNA-615-5p, which was confirmed by a dual luciferase reporter assay. The present study is consistent with previous studies, which demonstrated that microRNA-615-5p functions as a tumor suppressor (12), whereas HSF1 serves as a tumor promoter (13).

In previous studies, it has been identified that microRNA-615-5p functions as a tumor suppressor in pancreatic ductal adenocarcinoma (9,14). Furthermore, microRNA-615 may inhibit prostate cancer cell proliferation and invasion by directly targeting cyclin D2 (15). MicroRNA-615 has also been indicated to be a tumor suppressor that may inhibit breast cancer carcinogenesis by suppressing RAC-b serine/threonine-protein kinase expression (7). In the present study, the results of the cell proliferation and apoptosis assays demonstrated that microRNA-615-5p serves as a tumor suppressor in breast cancer, which is consistent with the aforementioned previous studies.

MicroRNAs typically regulate cell proliferation and apoptosis by targeting specific genes. An association of HSF1 with oncogenesis has previously been identified (16). A number of previous studies have demonstrated that HSF1 is overexpressed in various types of cancer, including hepatocellular carcinoma (17), colorectal cancer (18), breast cancer (19) and others (20-24). In the present study, proliferation- and 

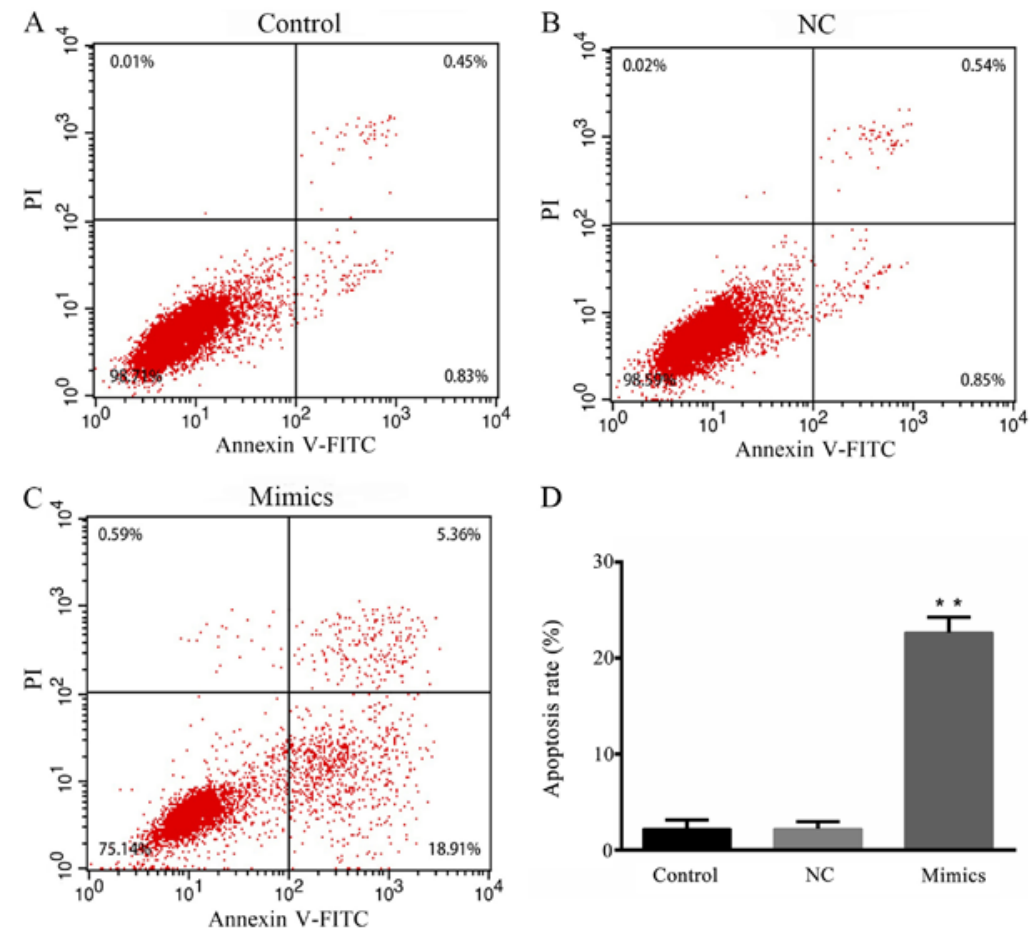

$\mathrm{D}$

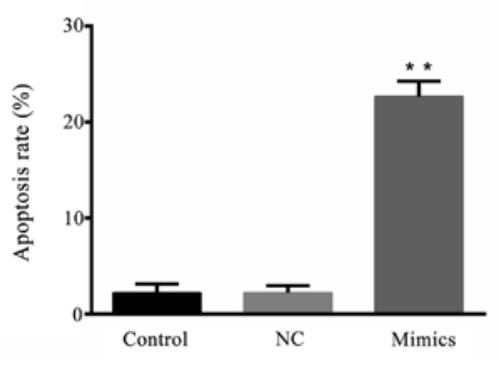

Figure 4. Effect of microRNA-615-5p on the apoptosis of MCF-7 cells. Apoptosis of the (A) control group, (B) NC and (C) microRNA-615-5p mimics group. (D) Quantified results of the flow cytometric analysis. ${ }^{* *} \mathrm{P}<0.01$, mimics vs. NC group. Control, untransfected cells; mimics, microRNA-615 mimics-transfected cells; NC, microRNA-615-5p negative control-transfected cells.
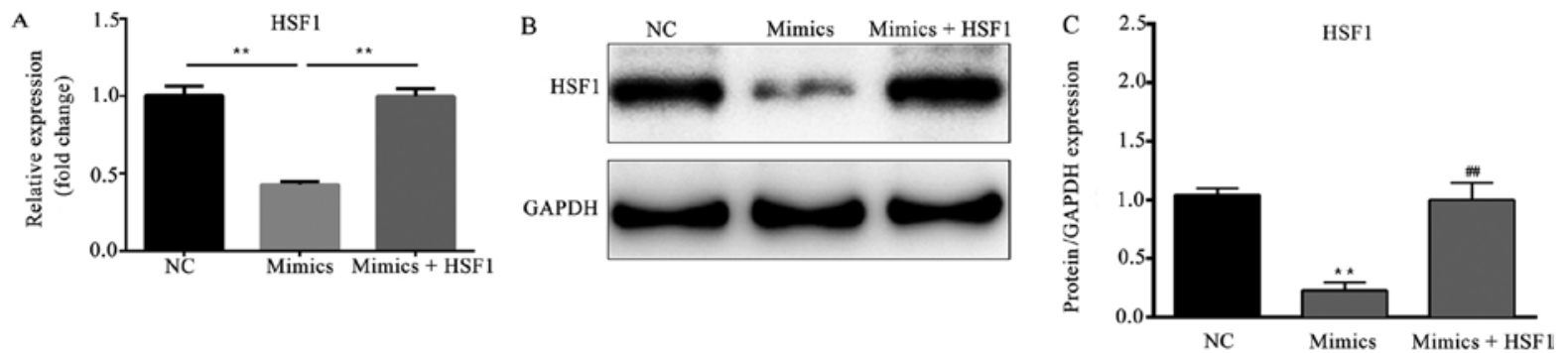

Figure 5. HSF1 overexpression overcomes the microRNA-615-5p-induced suppression of HSF1. (A) The mRNA expression levels of HSF1 following transfection. ${ }^{* *} \mathrm{P}<0.01$ as indicated. (B) Representative western blots showing the protein expression levels of HSF1 following transfection and (C) quantified HSF1 protein/GAPDH expression. ${ }^{* * *} \mathrm{P}<0.01$, mimics vs. NC group; ${ }^{\# /} \mathrm{P}<0.01$, mimics + HSF1 vs. mimics group. NC, microRNA-615-5p negative control-transfected cells; mimics, microRNA-615-5p mimics-transfected cells; mimics + HSF1, cells transfected with microRNA-615-5p mimics and pcDNA3.1-HSF1. HSF1, heat shock factor 1; GAPDH, glyceraldehyde 3-phosphate dehydrogenase.

A

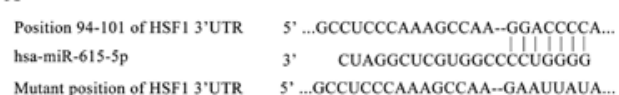

B

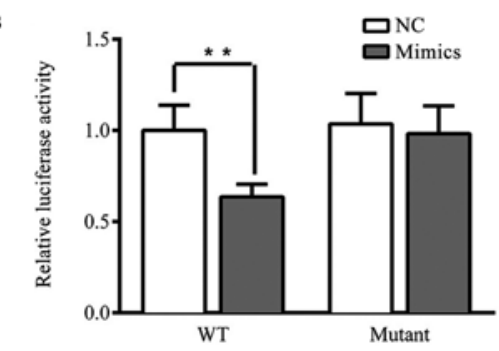

Figure 6. MicroRNA-615-5p targets HSF1. (A) Sequence alignment of the paired site of the 3'-UTR of microRNA-615-5p and HSF1. (B) Activity of the luciferases in different groups. ${ }^{* *} \mathrm{P}<0.01$, mimics vs. $\mathrm{NC}$ group. miR, microRNA; WT, wild-type; mimics, microRNA-615-5p mimics-transfected cells; NC, microRNA-615-5p mimics negative control-transfected cells; HSF1, heat shock factor 1; UTR, untranslated region. apoptosis-associated factors, namely Bcl-2, cyclin D1, PCNA and Bax, were evaluated using RT-qPCR and western blot analysis. The results of the western blot analysis indicate that HSF1 may function as an oncogene in breast cancer.

PCNA is a cell cycle marker that serves a role in the regulation of the cell proliferation process, and was first identified by Miyachi et al (25). Several studies have demonstrated that PCNA upregulation may promote breast cancer cell proliferation (26-28). Furthermore, a study observed that loss of HSF1 reduced the expression of PCNA in vivo (29). Cyclin D1 overexpression has been reported to correlate with early cancer onset and tumor progression (30). Furthermore, cyclin D1 was found to be overexpressed in breast cancer tissues, suggesting that it may serve as a potential biomarker (31). A number of studies have indicated that the suppression of cyclin D1 may inhibit breast cancer cell proliferation (32-34). Furthermore, the forced expression of HSF1 has been shown to increase 

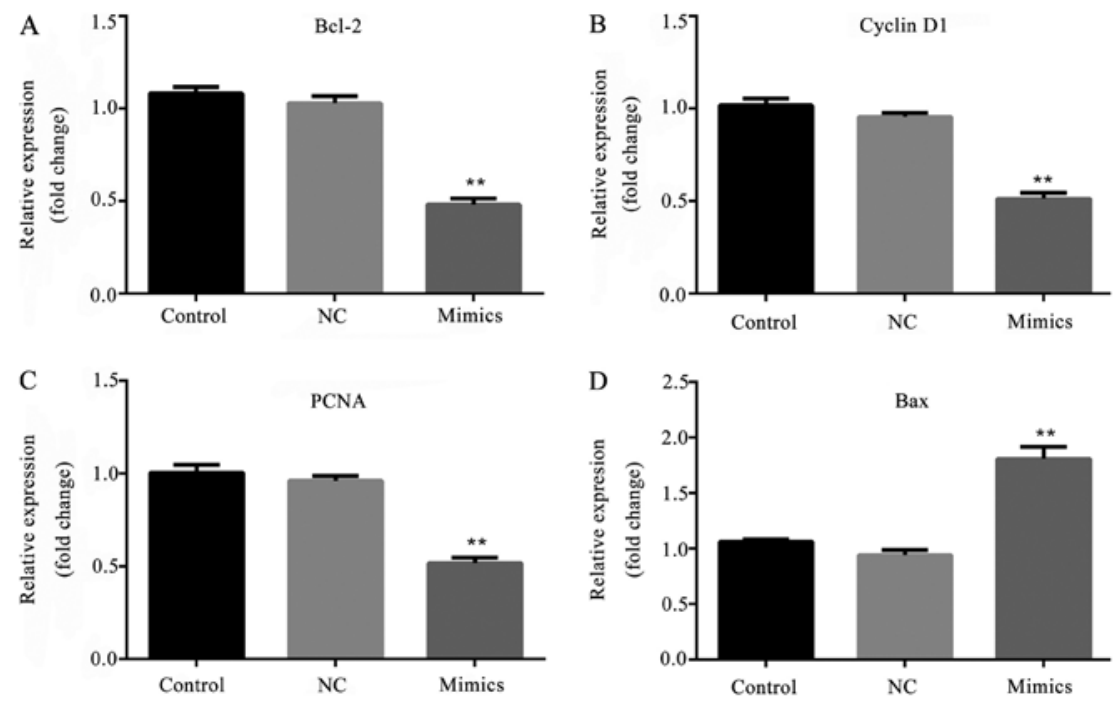

Figure 7. Effect of microRNA-615-5p on the mRNA expression levels of proliferation- and apoptosis-associated factors. The mRNA expression levels of (A) Bcl-2, (B) cyclin D1, (C) PCNA and (D) Bax. ${ }^{* *} \mathrm{P}<0.01$, mimics vs. NC group. Control, untransfected cells; NC, microRNA-615-5p negative control-transfected cells; mimics, microRNA-615-5p mimics-transfected cells; Bcl-2, B-cell lymphoma 2; PCNA, proliferating cell nuclear antigen; Bax, bcl-2-like protein 4.
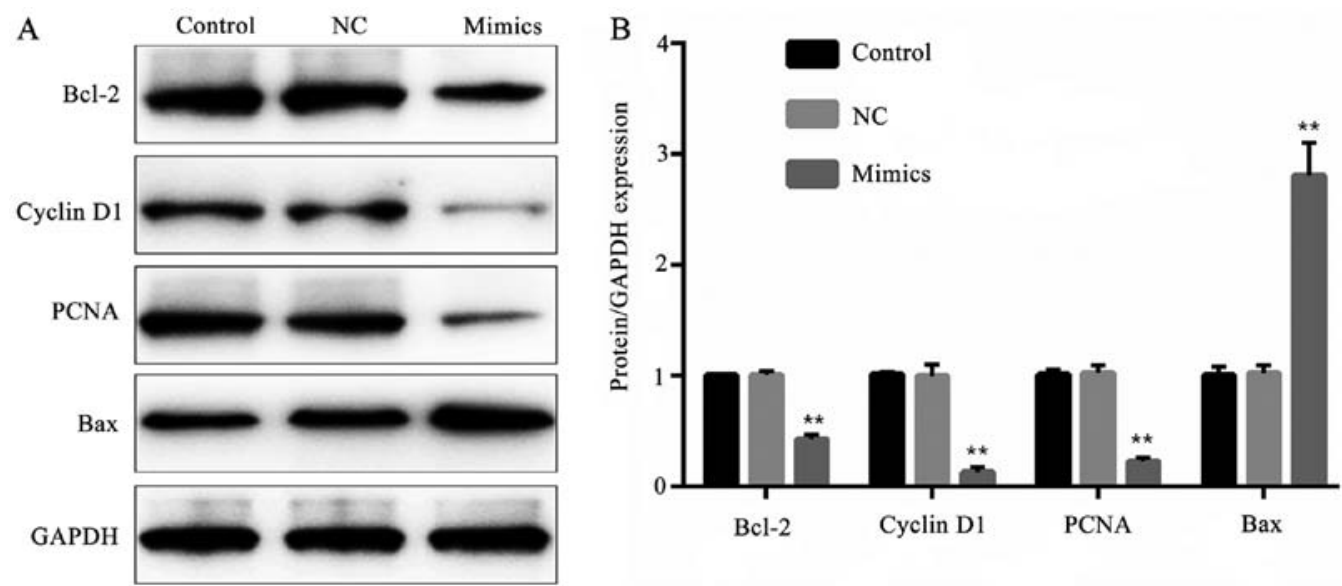

Figure 8. Effect of microRNA-615-5p on protein expression levels of proliferation- and apoptosis-associated factors. (A) The protein expression levels of Bcl-2, cyclin D1, PCNA and Bax detected by western blot assay. (B) Quantified protein/GAPDH expression levels in different groups. ${ }^{* *} \mathrm{P}<0.01$, mimics vs. NC group. Control, untransfected cells; NC, microRNA-615-5p negative control-transfected cells; mimics, microRNA-615-5p mimics-transfected cells; Bcl-2, B-cell lymphoma 2; PCNA, proliferating cell nuclear antigen; Bax, bcl-2-like protein 4; GAPDH, glyceraldehyde 3-phosphate dehydrogenase.

the expression of cyclin D1 (35). In the present study, it was identified that the expression levels of HSF1, PCNA and cyclin D1 were decreased following transfection with microRNA-615-5p-mimics. Therefore, it is hypothesized that microRNA-615-5p may inhibit breast cancer cell proliferation by targeting HSF1, which may decrease the expression levels of PCNA and cyclin D1.

Bcl-2 is recognized as an important factor with anti-apoptotic effects and was originally identified in human follicular B cell lymphoma (36). Bcl-2 expression has been revealed to be downregulated in triple-negative breast cancer (37,38). Wang et al (39) demonstrated that HSF1 knockdown was able to restrain the expression of $\mathrm{Bcl}-2$ in breast cancer. Bax is a proapoptotic protein associated with cell apoptosis $(40,41)$. The increased expression of Bax has been confirmed to promote breast cancer cell apoptosis $(42,43)$. In addition, Lou et al (44) demonstrated that HSF1 knockdown increased the expression of Bax. The results of the present study demonstrated that the expression of $\mathrm{Bcl}-2$ was decreased whereas that of Bax was increased when the cells were transfected with microRNA-615-5p mimics. Therefore, it is hypothesized that microRNA-615-5p may promote breast cancer cell apoptosis by targeting HSF1, which may decrease the expression of the anti-apoptotic protein $\mathrm{Bcl}-2$ and increase the expression of the proapoptotic protein Bax.

However, a previous study reported that insulin-like growth factor 2 (IGF2) is directly downstream of microRNA-615-5p (45). MicroRNA-615-5p may inhibit hepatocellular carcinoma cell invasion by directly suppressing IGF2 (46). In addition, IGF2 has been found to be upregulated in breast cancer (47), indicating that microRNA-615-5p may also regulate breast cancer cell proliferation and apoptosis via interaction with IGF2. Therefore, whether or not the microRNA-615-5p/IGF2 axis participates in the regulation of 
breast cancer cell proliferation and apoptosis requires further investigation. Other studies have indicated that HSF1 is downstream of human epidermal growth factor receptor 2 (HER2) and could be activated by HER $2(48,49)$. Therefore, the interaction of microRNA-615-5p and HER2 in the regulation of breast cancer cell proliferation and apoptosis remains unclear and also requires further investigation.

In conclusion, the present results demonstrated that microRNA-615-5p promoted the apoptosis of breast cancer cells and inhibited their growth by downregulating the expression levels of HSF1, Bcl-2, PCNA and cyclin D1, and increasing the expression of Bax. Therefore, targeting microRNA-615-5p is potentially a promising method for the treatment of breast cancer. However, two limitations remain: i) The underlying targeted relationship between microRNA-615-5p and HER2 requires further elucidation, and ii) further investigation of HER-positive breast cancer cell lines is necessary.

\section{Acknowledgements}

Not applicable.

\section{Funding}

No funding was received.

\section{Availability of data and materials}

The datasets used and/or analyzed during the current study are available from the corresponding author on reasonable request.

\section{Authors' contributions}

KL designed the experiments, analyzed the patient data and purchased the reagents. RM performed the examination, and was a major contributor in writing the manuscript. Both authors read and approved the final manuscript.

\section{Ethics approval and consent to participate}

The present study was approved by the Ethics Committee of Qilu Hospital of Shandong University (Jinan, China). Written consent was obtained from each patient.

\section{Patient consent for publication}

Not applicable.

\section{Competing interests}

The authors declare that they have no competing interests.

\section{References}

1. Torre LA, Bray F, Siegel RL, Ferlay J, Lortet-Tieulent J and Jemal A Global cancer statistics, 2012. CA Cancer J Clin 65: 87-108, 2015.

2. Hesari A, Azizian M, Darabi H, Nesaei A,Hosseini SA, Salarinia R, Motaghi AA and Ghasemi F: Expression of circulating miR-17, miR-25, and miR-133 in breast cancer patients. J Cell Biochem, Nov 28, 2018 (Epub ahead of print). doi: 10.1002/jcb.27984.
3. Farazi TA, Hoell JI, Morozov P and Tuschl T: MicroRNAs in human cancer. Adv Exp Med Biol 774: 1-20, 2013.

4. Dalmay T: Mechanism of miRNA-mediated repression of mRNA translation. Essays Biochem 54: 29-38, 2013.

5. Ji CZ, Han SH and Xing YF: Overexpression of miR-3196 suppresses cell proliferation and induces cell apoptosis through targeting ERBB3 in breast cancer. Eur Rev Med Pharmacol Sci 22: 8383-8390, 2018.

6. Lu K, Wang J, Song Y, Zhao S, Liu H, Tang D, Pan B, Zhao H and Zhang Q: miRNA-24-3p promotes cell proliferation and inhibits apoptosis in human breast cancer by targeting p27Kip1. Oncol Rep 34: 995-1002, 2015.

7. Bai Y, Li JY, Li J, Liu YH and Zhang B: miR-615 inhibited cell proliferation and cell cycle of human breast cancer cells by suppressing of AKT2 expression. Int J Clin Exp Med 8: 3801-3808, 2015.

8. Dong Y, Huo X, Sun R, Liu Z, Huang M and Yang S: lncRNA Gm15290 promotes cell proliferation and invasion in lung cancer through directly interacting with and suppressing the tumor suppressor miR-615-5p. Biosci Rep 38: pii: BSR20181150, 2018.

9. Sun Y, Zhang T, Wang C, Jin X, Jia C, Yu S and Chen J: miRNA-615-5p functions as a tumor suppressor in pancreatic ductal adenocarcinoma by targeting AKT2. PLoS One 10: e0119783, 2015.

10. Livak KJ and Schmittgen TD: Analysis of relative gene expression data using real-time quantitative PCR and the 2(-Delta Delta C(T)) method. Methods 25: 402-408, 2001.

11. Agarwal V, Bell GW, Nam JW and Bartel DP: Predicting effective microRNA target sites in mammalian mRNAs. Elife 4, 2015.

12. Pu HY, Xu R, Zhang MY, Yuan LJ, Hu JY, Huang GL and Wang HY: Identification of microRNA-615-3p as a novel tumor suppressor in non-small cell lung cancer. Oncol Lett 13: 2403-2410, 2017.

13. Asano Y, Kawase T, Okabe A, Tsutsumi S, Ichikawa H, Tatebe S, Kitabayashi I, Tashiro F, Namiki H, Kondo T, et al: IER5 generates a novel hypo-phosphorylated active form of HSF1 and contributes to tumorigenesis. Sci Rep 6: 19174, 2016.

14. Gao W, Gu Y, Li Z, Cai H, Peng Q, Tu M, Kondo Y, Shinjo K, Zhu Y, Zhang J, et al: miR-615-5p is epigenetically inactivated and functions as a tumor suppressor in pancreatic ductal adenocarcinoma. Oncogene 34: 1629-1640, 2015.

15. Huang FY, Zhao HJ, Du ZJ and Jiang H: miR-615 inhibits prostate cancer cell proliferation and invasion by directly targeting Cyclin D2. Oncol Res 27: 293-299, 2019.

16. Naresh DJ and Nadav B: Reconstruction of temporal activity of microRNAs from gene expression data in breast cancer cell line. BMC Genomics 16: 1077, 2015.

17. Fang F, Chang R and Yang L: Heat shock factor 1 promotes invasion and metastasis of hepatocellular carcinoma in vitro and in vivo. Cancer 118: 1782-1794, 2012.

18. Cen H, Zheng S, Fang YM, Tang XP and Dong Q: Induction of HSF1 expression is associated with sporadic colorectal cancer. World J Gastroenterol 10: 3122-3126, 2004.

19. Santagata S, Hu R, Lin NU, Mendillo ML, Collins LC, Hankinson SE, Schnitt SJ, Whitesell L, Tamimi RM, Lindquist S and Ince TA: High levels of nuclear heat-shock factor 1 (HSF1) are associated with poor prognosis in breast cancer. Proc Natl Acad Sci USA 108: 18378-18383, 2011.

20. Chen FY, Dong Z, Xia Y, Tang J, Peng L, Wang S and Lai D: Nucleoside analog inhibits microRNA-214 through targeting heat-shock factor 1 in human epithelial ovarian cancer. Cancer Sci 104: 1683-1689, 2013.

21. Dai C, Santagata S, Tang Z, Shi J, Cao J, Kwon H, Bronson RT, Whitesell L and Lindquist S: Loss of tumor suppressor NF1 activates HSF1 to promote carcinogenesis. J Clin Invest 122: 3742-3745, 2012

22. Heimberger T, Andrulis M, Riedel S, Stühmer T, Schraud H, Beilhack A, Bumm T, Bogen B, Einsele H, Bargou RC and Chatterjee M: The heat shock transcription factor 1 as a potential new therapeutic target in multiple myeloma. $\mathrm{Br} \mathrm{J}$ Haematol 160: 465-476, 2013.

23. Ishiwata J, Kasamatsu A, Sakuma K, Iyoda M, Yamatoji M, Usukura K, Ishige S, Shimizu T, Yamano Y, Ogawara K, et al: State of heat shock factor 1 expression as a putative diagnostic marker for oral squamous cell carcinoma. Int J Oncol 40: 47-52, 2012.

24. Hoang AT, Huang J, Rudra-Ganguly N, Zheng J, Powell WC, Rabindran SK, Wu C and Roy P: A novel association between the human heat shock transcription factor 1 (HSF1) and prostate adenocarcinoma. Am J Pathol 156: 857-864, 2000. 
25. Miyachi K, Fritzler MJ and Tan EM: Autoantibody to a nuclear antigen in proliferation cells. J Immunol 121: 2228-2234, 1978.

26. Liao XH,Lu DL, Wang N,Liu LY, Wang Y,Li YQ, Yan TB, Sun XG, $\mathrm{Hu} \mathrm{P}$ and Zhang TC: Estrogen receptor $\alpha$ mediates proliferation of breast cancer MCF-7 cells via a p21/PCNA/E2F1-dependent pathway. FEBS J 281: 927-942, 2014.

27. Li T, Zhang C, Ding Y, Zhai W, Liu K, Bu F, Tu T, Sun L, Zhu W, Zhou F, et al: Umbilical cord-derived mesenchymal stem cells promote proliferation and migration in MCF-7 and MDA-MB-231 breast cancer cells through activation of the ERK pathway. Oncol Rep 34: 1469-1477, 2015.

28. Wu J, Li H, Wang X, Zhang X, Liu W, Wang Y, Zhang Y, Pan H, Wang Q and Han Y: Effect of polysaccharide from Undaria pinnatifida on proliferation, migration and apoptosis of breast cancer cell MCF7. Int J Biol Macromol 121: 734-742, 2019.

29. Min JN, Huang L, Zimonjic DB, Moskophidis D and Mivechi NF: Selective suppression of lymphomas by functional loss of Hsf1 in a p53-deficient mouse model for spontaneous tumors. Oncogene 26: 5086-5097, 2007.

30. Diehl JA: Cycling to cancer with cyclin D1. Cancer Biol Ther 1: 226-231, 2002

31. He Y, Liu Z, Qiao C, Xu M, Yu J and Li G: Expression and significance of Wnt signaling components and their target genes in breast carcinoma. Mol Med Rep 9: 137-143, 2014.

32. Qin H and Liu W: MicroRNA-99a-5p suppresses breast cancer progression and cell-cycle pathway through downregulating CDC25A. J Cell Physiol 234: 3526-3537, 2019.

33. Song X, Wu JQ, Yu XF, Yang XS and Yang Y: Trichostatin A inhibits proliferation of triple negative breast cancer cells by inducing cell cycle arrest and apoptosis. Neoplasma 65: 898-906, 2018.

34. Chi Y, Xu H, Wang F, Chen X, Shan Z, Sun Y and Fan Q: ZKSCAN3 promotes breast cancer cell proliferation, migration and invasion. Biochem Biophys Res Commun 503: 2583-2589, 2018.

35. Sawai M, Ishikawa Y, Ota A and Sakurai H: The proto-oncogene JUN is a target of the heat shock transcription factor HSF1. FEBS J 280: 6672-6680, 2013

36. Escórcio-Dourado CS, Martins LM, Simplício-Revoredo CM, Sampaio FA, Tavares CB, da Silva-Sampaio JP, Borges US, Alves-Ribeiro FA, Lopes-Costa PV, Lima-Dourado JC and da Silva BB: Bcl-2 antigen expression in luminal A and triple-negative breast cancer. Med Oncol 34: 161, 2017.

37. Kallel-Bayoundh I, Hassen HB, Khabir A, Boujelbene N, Daoud J, Frikha M, Sallemi-Boundawara T, Aifa S and Rebai A: Bcl-2 expression and triple negative profile in breast carcinoma. Med Oncol 28 (Suppl 1): S55-S61, 2001.
38. de Ruijter TC, Veeck J, de Hoon JP, van Engeland M and Tjan-Heijnen VC: Characteristics of triple-negative breast cancer. J Cancer Res Clin Oncol 137: 183-192, 2011.

39. Wang X, Zhang D, Cao M, Ba J, Wu B, Liu T and Nie C: A study on the biological function of heat shock factor 1 proteins in breast cancer. Oncol Lett 16: 3821-3825, 2018.

40. Du L, Fei Z, Song S and Wei N: Antitumor activity of Lobaplatin against esophageal squamous cell carcinoma through caspase-dependent apoptosis and increasing the $\mathrm{Bax} / \mathrm{Bcl}-2$ ratio. Biomed Pharmacother 95: 447-452, 2017.

41. Yang F, Yu Y, Lei Q, Zeng A, Li Y, Xie Y, Ye T and Wei Y: Lobaplatin arrests cell cycle progression, induces apoptosis and impairs migration and invasion in B16-F10 melanoma cell line in vitro. Biomed Pharmacother 69: 402-408, 2015.

42. Lapierre M, Linares A, Dalvai M, Duraffourd C, Bonnet S, Boulahtouf A, Rodriguez C, Jalaquier S, Assou S, Orsetti B, et al: Histone deacetylase 9 regulates breast cancer cell proliferation and the response to histone deacetylase inhibitors. Oncotarget 7: 19693-19708, 2016.

43. Quisbert-Valenzuela EO and Calaf GM: Apoptotic effect of noscapine in breast cancer cell lines. Int J Oncol 48: 2666-2674, 2016.

44. Lou Q, Hu Y, Ma Y and Dong Z: Heat shock factor 1 induces crystallin- $\alpha \mathrm{B}$ to protect against cisplatin nephrotoxicity. Am J Physiol Renal Physiol 311: F94-F102, 2016.

45. Jiang Y, Zhang Y, Li F, Du X and Zhang J: CDX2 inhibits pancreatic adenocarcinoma cell proliferation via promoting tumor suppressor miR-615-5p. Tumor Biol 37: 1041-1049, 2016.

46. Song LJ, Zhang WJ, Chang ZW, Pan YF, Zong H, Fan QX and Wang LX: PU. 1 is identified as a novel metastasis suppressor in hepatocellular carcinoma regulating the miR-615-5p/IGF2 axis Asian Pac J Cancer Prev 16: 3667-3671, 2015.

47. Shetty PJ, Movva S, Pasupuleti N, Vedicherlla B, Vattam KK, Venkatasubramaniam S, Ahuja YR and Hasan Q: Regulation of IGF2 transcript and protein expression by altered methylation in breast cancer. J Cancer Res Clin Oncol 137: 339-345, 2011.

48. Schulz R, Streller F, Scheel AH, Rüschoff J, Reinert MC, Dobbelstein M, Marchenko ND and Moll UM: HER2/ErbB2 activates HSF1 and thereby controls HSP90 clients including MIF in HER2-overexpressing breast cancer. Cell Death Dis 5: e980, 2014

49. Guettouche T, Boellmann F, Lane WS and Voellmy R: Analysis of phosphorylation of human heat shock factor 1 in cells experiencing a stress. BMC Biochem 6: 4, 2005. 